\title{
PERFIL SÓCIO DEMOGRÁFICO E OCUPACIONAL DOS PROFISSIONAIS DE ENFERMAGEM DO HEMOCENTRO COORDENADOR DE PALMAS
}

\author{
JAQUELINE MIRANDA BARROS SILVA, \\ LÍCIA MAGNA RODRIGUES SANTOS OLIVEIRA, \\ JAMINUAN AUCÊ DO NASCIMENTO MAMEDE, \\ TATIANA PERES SANTANA PORTO WANDERLEY, \\ SOLANGE MARIA MIRANDA SILVA, \\ TATYANNI PEIXOTO RODRIGUES.
}

\begin{abstract}
RESUMO - Atualmente há uma preocupação maior com o indivíduo nas relações profissionais e pessoais com vistas a um conhecimento melhor deste indivíduo, bem como da sua satisfação no trabalho. Esta pesquisa teve por objetivo traçar o perfil sócio demográfico e ocupacional dos profissionais de enfermagem do Atendimento ao Doador de Sangue. Trata-se de um estudo exploratório de cunho quantitativo que teve como amostra 34 profissionais de enfermagem. A coleta foi realizada em setembro, no Hemocentro Coordenado de Palmas, após aprovação do Comitê de Ética. Houve predominância do sexo feminino com faixa etária entre 31-40 anos. Apesar da maioria serem técnicos de enfermagem, 58,8\% possuem nível superior, são experientes e atuam no HCP de 1 a 5 anos, a maioria possui apenas um vínculo, contudo desempenham papeis em outros cenários. Cabe, portanto, o desenvolvimento de pesquisas que mensurem o nível de satisfação destes trabalhadores a fim de uma excelência no serviço prestado..
\end{abstract}

PALAVRAS-CHAVE - Enfermagem; Saúde do Trabalhador; Características da População.

\section{INTRODUÇÃO}

No compasso histórico que envolve as relações de trabalho, nas últimas décadas houve uma preocupação maior com a relação indivíduo - trabalho, principalmente, com seu comportamento diante da produtividade e sua satisfação. Em decorrência disso, a qualidade de vida no trabalho é notória no âmbito organizacional, apesar de muitos ainda ignorá-la.

Porém, hoje, na visão do trabalhador, é essencial no seu ofício, a busca não só pela compensação financeira, mas principalmente pelas condições adequadas para desenvolvimento de suas habilidades, potencialidades livres de danos físicos, psíquicos e sociais, ou seja, a qualidade de vida no trabalho [1].

Nesse contexto o trabalho em equipe depende de características tangíveis para sua execução: ambiente de apoio, capacidade adequada ás necessidades do cargo, metas superiores e premiação da equipe, são algumas delas [2].

A preocupação com a Qualidade de Vida no Trabalho - QVT, principalmente no mundo Ocidental, não necessariamente é pelo conforto do sujeito, mas principalmente pelo interesse econômico da Instituição. No entanto, essa realidade no Brasil, em decorrência da globalização, vem gerando mudanças, sendo necessário atentar não apenas para qualidade dos produtos e serviços, mas também para o pro- cesso contínuo na busca de pessoas motivadas pelo constante desejo de fazer e poder fazer [3].

Assim, conhecer o perfil da equipe de enfermagem tornase imprescindível a fim de propiciar condições adequadas de trabalho que possibilitem a satisfação desse indivíduo garantindo a organização e o alcance de resultados tangíveis, ao passo que o homem capacitado e envolvido com a instituição produz efetivamente bem.

\section{OBJETIVO}

Traçar o perfil sócio demográfico e ocupacional dos profissionais de enfermagem do Atendimento ao Doador de Sangue do Hemocentro Coordenador de Palmas - TO.

\section{MATERIAL E MÉTODO}

Trata-se de um estudo exploratório com abordagem quantitativa. A população foi composta por 218 profissionais que compõe o Hemocentro Coordenador de Palmas - HCP e a amostra por 34 profissionais de enfermagem que fazem parte do Atendimento ao Doador de Sangue do Hemocentro Coordenador de Palmas. Os dados foram coletados no mês setembro de 2014, no setor de Atendimento ao Doador de Sangue do Hemocentro Coordenador de Palmas. Esta pesquisa seguiu os preceitos éticos e legais da Res. CNS 
n.466/2012 que normatiza pesquisas envolvendo seres humanos [4], conforme parecer $\mathrm{n}^{\mathbf{0}} 774.591$.

\section{RESULTADOS E DISCUSSÃO}

Dos 34 profissionais de enfermagem do ATDO, 07 são enfermeiros $(20,6 \%)$ e 27 técnicos de enfermagem $(79,4 \%)$.

$\mathrm{Na}$ análise dos dados em relação ao sexo dos participantes o resultado amostral foi predominantemente do sexo feminino perfazendo um total de $91,2 \%$, fato este evidente e persistente na enfermagem brasileira. Nesse contexto algumas interpretações são conexas, ao passo que historicamente o cuidar refere-se uma qualidade feminina, na qual partem da hipótese que homens não têm desenvoltura para cuidar, visto que nos processos de recrutamento, no mercado de trabalho atesta por precedência feminina [5].

Portanto, na equipe do ATDO do HCP essa realidade não foi diferente no qual também impera o sexo feminino, apesar deste serviço ter como foco pessoas sadias não podese esquecer que o cuidado atua primordialmente a nível preventivo, a fim de que não se chegue a um estágio mórbido, considerando as possíveis reações adversas inerentes a doação de sangue.

No que diz respeito à idade dos profissionais pode-se observar na figura 1 os resultados deste indicador
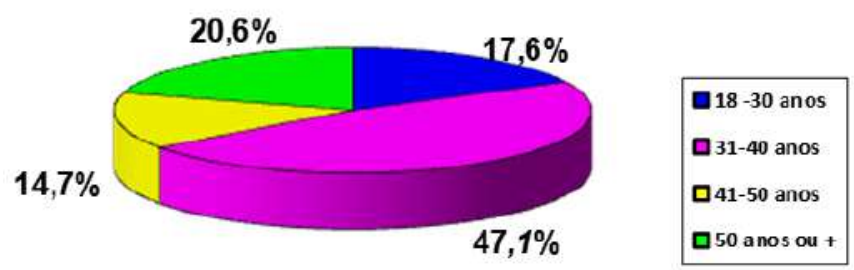

Figura 1. Distribuição dos profissionais de enfermagem conforme idade. Palmas /TO, 2014.

Fonte: Dados da pesquisa de campo. Palmas/TO, 2014.

Houve uma predominância da faixa etária entre 31 a 40 anos, perfazendo um percentual de $47,1 \%$ dos profissionais de enfermagem do ATDO. Esse achado foi condizente com pesquisa realizada com os profissionais do Hemocentro Regional de Pelotas/RS, no qual também prevaleceu a mesma faixa etária6. Esse dado é pertinente se levar em conta que o maior percentual da força de trabalho no Brasil no último censo é na faixa etária entre 30 a 59 anos [7].

No que se refere ao estado civil, conforme demonstrado na figura 2, verificou-se que $47,1 \%$ dos participantes são casados, $26,5 \%$ solteiros, $14,7 \%$ união estável e $11,8 \%$ divorciados.

Portanto, houve uma predominância do status casado, resultado este relevante se considerar que a maior parte da população brasileira encontra-se nesta condição [7] (IBGE, 2010). Mulheres casadas que têm vínculo trabalhista são mais benéficas fisicamente e psicologicamente em relação às mulheres sem trabalho [8].

Em relação à escolaridade dos profissionais do ATDO, a figura 3 demonstra que $58,8 \%$ possuem nível superior com-
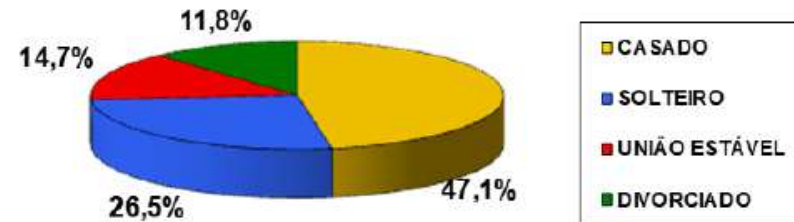

Figura 2. Distribuição dos profissionais de enfermagem conforme estado civil. Palmas/ TO, 2014.

Fonte: Dados da pesquisa de campo. Palmas/TO, 2014.

pleto. Esse dado caracteriza uma maior qualificação desse profissional e consequentemente maior qualidade na execução dos serviços da Instituição, o que possibilita perspectivas desse profissional no que tange a valorização de sua formação superior no contexto institucional.

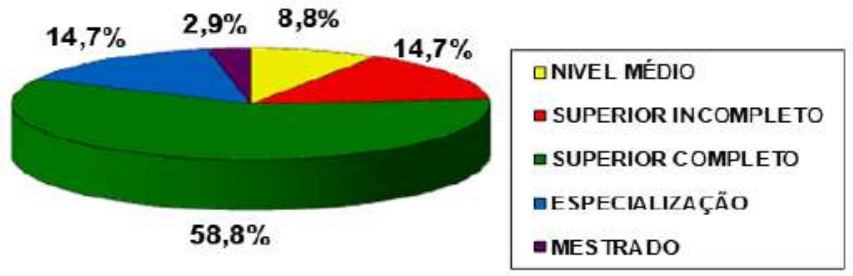

Figura 3. Distribuição dos profissionais de enfermagem conforme escolaridade. Palmas/ |TO, 2014

Fonte: Dados da pesquisa de campo. Palmas/TO, 2014.

Esse índice elevado de profissionais que têm nível superior completo é reflexo da exigência organizacional vigente no contexto contemporâneo, em que a qualidade dos serviços se faz necessário a partir da qualificação profissional bem como do desenvolvimento das pessoas para funções a serem assumidas futuramente [9].

Dentre os 07 enfermeiros, duas possuem outra formação, são pedagogas, e dentre os 27 técnicos de enfermagem, 14 apresentam nível superior, dentre as seguintes formações: RH, Pedagogia, Administração, Matemática, Serviço Social, História, Educação Física e Enfermagem. Esse dado, de certa forma, reflete positivamente na qualidade do serviço, haja vista que os profissionais buscam conhecimento em outras áreas de formação contribuindo, assim, para o seu crescimento pessoal e profissional.

Portanto, para manter como diferencial a qualidade dos serviços, a organização necessita quase sempre contar com pessoas habilitadas [10].

Como demonstra a figura $4,50,0 \%$ dos profissionais ATDO tem mais de 10 anos de atuação na área da saúde.

Esse dado indica certa experiência profissional, pois a maioria apresentou mais de 10 anos no serviço na área da saúde, fator importante em uma equipe em que a qualidade dos serviços é o objetivo maior da instituição, no que tange a fidelização da matéria prima dos Bancos de Sangue: o Doador. Ao passo que o esforço de estratégia de mercado dos bancos de sangue é transformar a primeira doação em doação contínua, ou seja, aumentar gradativamente as doa- 


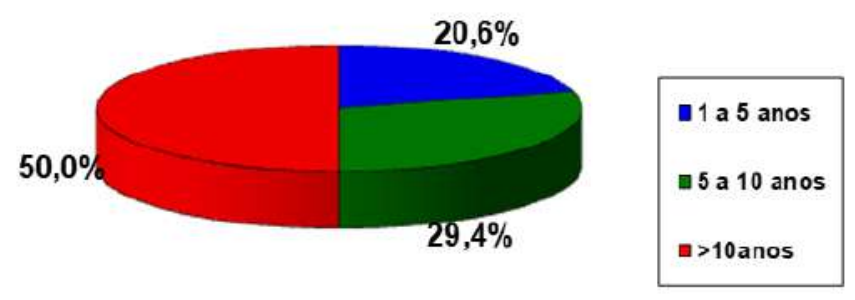

Figura 4. Tempo de atuação na área da saúde dos profissionais de Enfermagem. Palmas/ TO, 2014.

Fonte: Dados da pesquisa de campo. Palmas/TO, 2014.

ções voluntárias e espontâneas com consequente fidelização do doador [11].

Além da segurança com o uso de material descartável, os doadores também ressaltam sobre o atendimento, a habilidade, o conhecimento e a tranquilidade passada pela equipe como aspectos altamente positivo, gerando confiança no serviço e conseguinte retorno desse doador. Portanto a experiência com qualidade desse colaborador na assistência em todo processo de doação de sangue reflete efetivamente na fidelização do doador [12].

No que diz respeito ao tempo que pertence à equipe do ATDO, a pesquisa obteve os resultados, de acordo com a figura 5 .

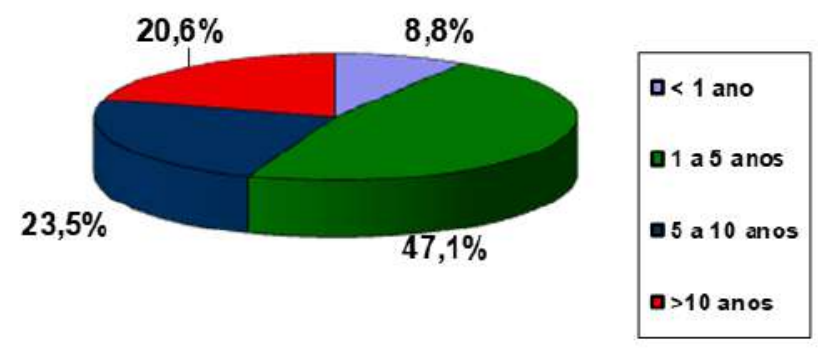

Figura 5. Tempo que faz parte da equipe do ATDO - Palmas- TO/2014 Fonte: Dados da pesquisa de campo. Palmas/TO, 2014.

Como pode-se observar na figura 5, detectou-se um maior contingente de profissionais entre 1 a 5 anos de atuação, ou seja, $47,1 \%$ do total da amostra. Fato este que indica que quase a maioria dos profissionais desta equipe já chegou com certa experiência profissional, no entanto considerados jovens em relação ao tempo de ATDO. Pesquisa em um Hemocentro de outro Estado encontrou em seu estudo o período semelhante ao desta pesquisa, no qual o tempo de serviço foi de 1 a 4 anos [6].

Em relação ao tipo de vínculo trabalhista, 97,1\% dos profissionais são concursados. É importante lembrar que, por se tratar de uma Instituição Pública essa realidade é vigente, e considerada como um fator positivo no que se refere à estabilidade no emprego, no entanto, esse dado pode refletir negativamente, gerando certo comodismo desse profissional no que tange a educação continuada, comprometendo, assim, a qualidade do serviço, embora nesta pesquisa tenha sido detectado como ponto favorável, pois a maioria dos profissionais apresenta nível superior $(58,8 \%)$.

Esse dado aparentemente é conveniente se levar em conta a segurança e manutenção do emprego, ou seja, vantagem do ponto de vista social e econômico, ao passo que traz tranquilidade a vida do indivíduo. No entanto, nem sempre a estabilidade no emprego promove um bom desempenho do trabalhador estatutário em que infração de normas, ineficiência, desmotivação, são pontos negativos e comuns presentes nas organizações públicas e conseguinte comprometimento na qualidade dos serviços. E, para isso, precisa-se criar estratégias de educação que encorajem a participação dos trabalhadores e assim possibilitar a capacitação profissional, promovendo o desenvolvimento de habilidades e competências fortalecendo o processo de trabalho [13].

Já a análise quanto a outro vínculo trabalhista, $82,4 \%$ da amostra não apresenta outro vínculo, fato consideravelmente positivo, já que uma das causas de maior adoecimento do profissional de enfermagem é a sobrecarga de trabalho na qual, acomete esse profissional a um desgaste físico, psíquico inclusive social, já que o cansaço interfere diretamente nas relações sociais e interpessoais.

Embora a maioria dos profissionais possua apenas o Hemocentro como vínculo, cabe salientar que esses profissionais assumem atribuições em diversos cenários, dentre os quais serviços do lar, líder familiar, materno/paternos de certa forma somando dupla, tripla jornada de trabalho no âmbito geral.

Sendo assim, dentro do contexto profissional a iminência de esgotamento pessoal, desmotivação, ansiedade, frustração, ou seja, absoluta falta de energia conhecida por Burnout é o fenômeno que atinge de forma geral os profissionais que lidam diretamente com pessoas, com sobrecarga de trabalho associada não só pela inexistência de qualidade de vida no trabalho, mas também em conjunto com fatores pessoais estressantes [14].

\section{CONCLUSÃO}

A caracterização sócio-demográfica e ocupacional da equipe de enfermagem do ATDO definiu-se: como 91,2\% do sexo feminino, de faixa etária predominante entre 31-40 anos $(47,1 \%)$, casado $(47,1 \%)$. Apesar de a maioria ter formação técnica em enfermagem, desses a maioria $(58,8 \%)$ possui nível superior. 50,0\% dos profissionais tem mais de 10 anos de atuação na área de saúde e 47,1\% apresentaram entre 1 a 5 anos de tempo de atuação na equipe do ATDO. Dentre os profissionais $97,1 \%$ são concursados e $82,4 \%$ não possuem outro vínculo trabalhista.

Destarte, apesar da maioria dos profissionais terem apresentado formação técnica na sua área de atuação, além de experiência profissional na área da saúde, em especial no local em que atua, foi identificada nesta pesquisa uma sobrecarga de trabalho, no que tange a dupla ou tripla jornada enfrentada pela maioria dos participantes, a exemplo, atividades do lar.

Outro aspecto relevante a ser enfatizado foi a estabilidade do profissional no serviço, em detrimento da maioria ser 
concursado, entretanto, esse fator pode gerar certa fragilidade no que diz respeito à posição passiva na participação de programas de educação continuada.

Espera-se com esta pesquisa, que ela sirva de subsídios para novos estudos neste cenário de prática com vistas a um conhecimento mais aprofundado das relações e satisfação do trabalhador em busca de estratégias de motivação e, consequente excelência no serviço ofertado.

\section{Referências}

[1] Rodrigues MVC. Qualidade de Vida no Trabalho: evolução e análise no nível gerencial. Petrópolis: Vozes. 1994.

[2] Davis k, Newstrom J. Comportamento humano no trabalho: uma abordagem organizacional. v 2. São Paulo: Pioneira. 1992.

[3] Fernandes EC. Qualidade de vida no trabalho: como medir para melhorar. Casa da Qualidade Ltda. 1996.

[4] Brasil. Ministério da Saúde. Resolução do Conselho Nacional de Saúde. N 466/2012. Brasília: MS. 2012.

[5] Lopes MJM, Leal SMC. A feminização persistente na qualificação profissional da enfermagem brasileira. 2005. Cadernos Pagu. (24): 105-25.

[6] Garcia DF. Qualidade vida no Trabalho: a satisfação dos servidores do Hemocentro regional de Pelotas/RS. Escola de Administração UFRGS, Janeiro de 2012. Disponível em: http://www.lume.ufrgs.br/bitstream/handle/10183/67699/000870012.pdf. Acesso em 17/11/2014.

[7] IBGE. CENSO DEMOGRÁFICO 2010. Características da população e dos domicílios: resultados do universo. Rio de Janeiro: IBGE. 2010. Disponível em: http://www.ibge.gov.br/home/estatistica/populacao/censo2010/caracteristicas _da_populacao/resultados_do_universo.pdf. Acesso em: 30/10/2014.

[8] Possati IC, Dias MR. Multiplicidade de papéis da mulher e seus efeitos para o bem estar psicológico. 2002. Psicol. Reflex. Crít. 15 (2): 293-301.

[9] Chiavenato I. Gestão de Pessoas: o novo papel dos recursos humanos nas organizações. Rio de Janeiro: Campus. 1999.

[10] Cavalcante SMA. Treinamento como ferramenta estratégica para o crescimento organizacional. 2006. Univila. Disponível em: http://www.novomilenio.br/foco/1/artigo/4_ Artigo_ Treinamento Andre.pdf. Acesso em 29/10/2014.

[11] Brasil. Ministério da Saúde. Caderno de informação: sangue e hemoderivados: rede física, produção, gastos públicos com hemoterapia e consumo de hemoderivados/Ministério da Saúde. Brasília: MS, 2007.

[12] Ludwig ST, Rodrigues ACM. Doação de Sangue: uma Visão de Marketing Cad. Saúde Pública. 2005; 21 (3): 932-39.

[13] Guimarães AT, Vaghetti HH, Lunardi-Filho WDL, Gomes GC. Gerenciamento do pessoal de enfermagem com estabilidade no emprego: percepção de enfermeiros. Rev Bras Enferm. 2011.64 (5): 905-11.

[14] Lopes CCP, Ribeiro TP, Martinho, NJ. Síndrome de Burnout e sua relação com a ausência de qualidade de vida no trabalho do Enfermeiro. Enfermagem em Foco. 2012. 3 (2): 97-101.

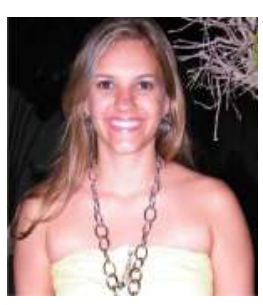

JAQUELINE MIRANDA BARROS SILVA

Enfermeira. Mestre em Enfermagem. Docente do Centro Universitário Luterano de Palmas CEULP.

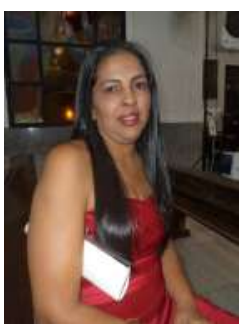

LÍCIA MAGNA RODRIGUES SANTOS OLIVEIRA

Graduada em Enfermagem pelo Centro Universitário Luterano de Palmas - CEULP/ULBRA. Atuando há 13 anos como Técnica de Enfermagem no Hemocentro Coordenador de Palmas.

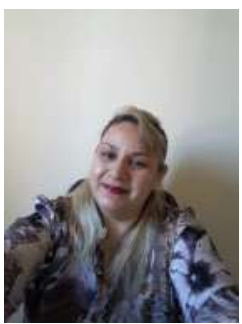

JAMINUAN AUCÊ DO NASCIMENTO MAMEDE

Enfermeira. Mestre em Enfermagem. Docente do Centro Universitário Luterano de Palmas CEULP. .

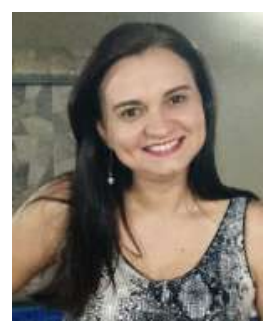

TATIANA PERES SANTANA PORTO WANDERLE

Enfermeira. Mestre em Enfermagem. Docente do Centro Universitário Luterano de Palmas CEULP.

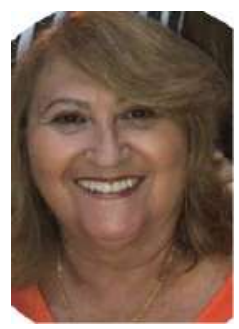

SOLANGE MARIA MIRANDA SILVA

Enfermeira. Doutora. Docente do Centro Universitário Luterano de Palmas - CEULP. .

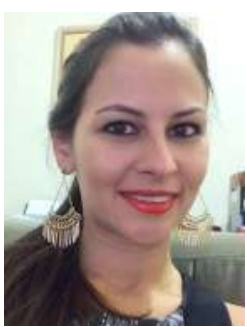

TATYANNI PEIXOTO RODRIGUES

Enfermeira. Doutora. Docente do Centro Universitário Luterano de Palmas - CEULP. 